\title{
Flipchip bonding of ultrahin Si dies onto PEN/PET substrates with low cost circuitry
}

Jeroen van den Brand, Roel Kusters, Mark Heeren, Bart van Remoortere, Andreas Dietzel Holst Centre/TNO - Netherlands Organisation for Applied Scientific Research, HTC31, Postbus 8550, 5605 KN Eindhoven, the Netherlands.

\begin{abstract}
All-printed, cost effective, smart electronic products are expected to be used in a wide range of applications and in large quantities in our society. The substrate material for these applications will be low cost materials like PEN or PET foils. For the functionality of the printed electronics product it often will still be required to integrate a Si chip. To keep the flexibility of the package and not to add too much to the thickness, the chip needs to be integrated into the product as a bare, thinned die. Because of the low temperature stability of the PEN and PET and the use of printed conductors it is necessary to interconnect the chip using an adhesive. The current paper specifically addresses the challenges associated with this. Research efforts will be discussed on the flip chip bonding of ultrathin (i.e. thickness $20 \mu \mathrm{m}$ ) bare chips on printed circuitry on both PEN and PET foils using a typical anisotropic conductive adhesive (ACA). Based on the results it can be concluded that a reproducible, low contact resistance and a good lifetime and flexural durability can be achieved over a wide range of bonding forces and temperatures.
\end{abstract}

\section{Introduction}

Recently a new class of flexible electronics is starting to emerge which is most effectively termed 'printed electronics'. This term often refers to all-printed, cost effective, smart electronic products that will find a wide range of applications in large quantities in our society. Examples include cheap sensor packages attached to food packaging to measure the ripeness of food, smart bandages that monitor the healing of wounds and smart active or passive RFID tags. These cost effective packages can include all-printed functional structures like conductive circuitry, OLED pixels, photodiodes and logics based on organic materials.

The substrate material will in most cases not be polyimide as commonly used in the more traditional flexible electronics. By using polyesters like PEN (polyethylene naphtalate) or PET (polyethylene teraphtalate), the substrate costs can be reduced by a factor of 5-10 [1]. A disadvantage of polyesters is however that they are considerably less thermally stable. PEN has a glass transition temperature $\left(\mathrm{T}_{\mathrm{g}}\right)$ of $\sim 130{ }^{\circ} \mathrm{C}$ and PET of $\sim 85{ }^{\circ} \mathrm{C}$ while poly(imide) has a $\mathrm{T}_{\mathrm{g}}$ of $\sim 350$ ${ }^{\circ} \mathrm{C}$ ) [1]. This limitation in thermal stability excludes many well established processes for making electronic products and/or renders the use of existing processes much more challenging.

A tangible example of such a printed electronics product is the disposable smart pill blister that is under development at the Holst Centre and its industrial partners. A photograph of a first prototype of it is shown in Figure 1. This smart blister is capable of registering and storing the date and time when a pill has been taken out, which is important for monitoring the patients medicine compliance. This functionality is made possible through an integrated ultrathin bare Si-based microprocessor typically having around 20 IO's and a size of 1 x $1 \mathrm{~mm}$, a thin printed battery and a printed antenna. It is expected that the market for these smart blisters will be several billion pieces per year at an added cost target for the electronics of around 1 euro per blister.

One of the key challenges in manufacturing of these blisters but also in other low cost printed electronic products is the integration and interconnection of the $\mathrm{Si}$ chip onto the low cost substrate. To keep the flexibility of the package and not to add too much to the thickness, the chip needs to be integrated into the product as a bare, thinned die. Because of the low temperature stability of the PEN and PET and the use of printed conductors it is necessary to interconnect the chip using an adhesive.

The current paper specifically addresses the challenges associated with this. Research efforts will be discussed on the flip chip bonding of ultrathin (i.e. thickness $20 \mu \mathrm{m}$ ) bare chips on both PEN and PET foils using a typical anisotropic conductive adhesive (ACA). The goal of the research was to obtain knowledge on the limitations of flip chip bonding on low cost substrates and to understand why these limitations exist.

Bonding on two types of low cost electronic circuitry will be discussed. For use in coarse pitch applications (i.e. pitches/line widths $>150 \mu \mathrm{m})$, bonding on conventional screen printed circuitry was investigated. For use in fine pitch applications (i.e. pitches/line widths below $50 \mu \mathrm{m}$ ) bonding on circuitry made with the 'embedded circuitry' process [2] was investigated. Embedded circuitry is a novel process developed at the Holst Centre which allows making fine pitch (down to $25 \mu \mathrm{m}$ ) electronic circuitry but still using standard screen printing pastes and equipment.

A summary of the relevant material and process specifications for the current work is given in Table 1.

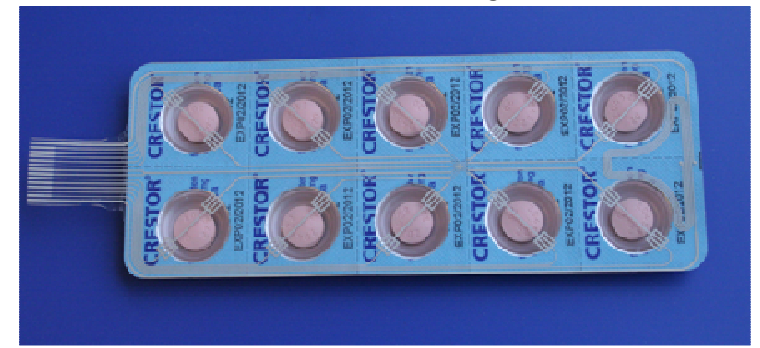

Figure 1. Photograph of one of first prototypes of smart medicine blister. The smart blister has an embedded ultrathin microprocessor, a printed antenna and a (printed) thin battery 


\begin{tabular}{|c|c|c|}
\hline \multicolumn{3}{|c|}{ conductive circuitry } \\
\hline type & $\begin{array}{l}\text { screen printed } \\
\text { circuitry }\end{array}$ & embedded circuitry \\
\hline line width & $150 \mu \mathrm{m}$ & $25 \mu \mathrm{m}$ \\
\hline line pitch & $300 \mu \mathrm{m}$ & $50 \mu \mathrm{m}$ \\
\hline paste & Dupont 5025 & Inktec TEC-PA-10 \\
\hline substrates & $\begin{array}{c}\text { PEN } \\
\mathrm{T}_{\mathrm{g}}=130^{\circ} \mathrm{C}, \mathrm{CTE}<\mathrm{Tg}= \\
10 \mathrm{ppm}, \mathrm{CTE}>\mathrm{Tg}=28 \\
\mathrm{ppm}\end{array}$ & $\begin{array}{c}\text { PEN } \\
\mathrm{T}_{\mathrm{g}}=130^{\circ} \mathrm{C}, \mathrm{CTE}<\mathrm{Tg}= \\
10 \mathrm{ppm}, \mathrm{CTE}>\mathrm{Tg}=28 \\
\mathrm{ppm}\end{array}$ \\
\hline \multicolumn{3}{|c|}{$\begin{array}{c}\mathrm{Tg}=85^{\circ} \mathrm{C}, \mathrm{CTE}<\mathrm{Tg}= \\
25 \mathrm{ppm}, \mathrm{CTE}>\mathrm{Tg}=60 \\
\mathrm{ppm}\end{array}$} \\
\hline \multicolumn{3}{|l|}{ test chip } \\
\hline type & daisy chain & daisy chain \\
\hline bumps & $8 \mu \mathrm{m}, \mathrm{Ni} / \mathrm{Au}$ & $8 \mu \mathrm{m}, \mathrm{Ni} / \mathrm{Au}$ \\
\hline IO's & 20 & 176 \\
\hline pitch & $300 \mu \mathrm{m}$ & $50 \mu \mathrm{m}$ \\
\hline thickness & $20 \mu \mathrm{m}$ & $20 \mu \mathrm{m}$ \\
\hline \multicolumn{3}{|c|}{ bonding settings } \\
\hline $\begin{array}{r}\text { temperature/ } \\
\text { time }\end{array}$ & $\begin{array}{c}100^{\circ} \mathrm{C} / 40 \mathrm{~s}, 120^{\circ} \mathrm{C} / 19 \mathrm{~s}, \\
150^{\circ} \mathrm{C} / 6 \mathrm{~s}, 170^{\circ} \mathrm{C} / 6 \mathrm{~s}\end{array}$ & $120^{\circ} \mathrm{C} / 19 \mathrm{~s}, 150^{\circ} \mathrm{C} / 6 \mathrm{~s}$ \\
\hline
\end{tabular}

Table 1. Process/component specifications as used in the current work

\section{Experimental}

Two different types of polyester foils were investigated. The PEN foil that was used was a $125 \mu \mathrm{m}$ thick thermally stabilized Dupont-Tejin Teonex Q65. The PET substrate that was used was a $120 \mu \mathrm{m}$ thick thermally stabilized foil from Agfa.

The largest portion of the work was performed on coarse pitch screen printed circuitry. Bonding on screen printed PEN and PET foils was investigated using a $2 \times 2$ mm IZM28 daisy chain test chip having 20 IO's, a pitch of $300 \mu \mathrm{m}$ and a thickness of $20 \mu \mathrm{m}$. A dedicated fanout circuitry was made and printed for this chip which allowed accurate 4 point $(4 \mathrm{p})$ measurements to be performed so as to obtain only information on the bumpcircuitry contact resistance. The flip chip bonding was performed using a Dr. Tresky T3200 semi-automatic bonder. First, a commercially available Delo AC163 epoxy-based ACA was dispensed on the foil at the bonding position of the chip. Then, the preheated tefloncoated bonding tool with the attached chip was aligned and pressed down with the appropriate force onto the foil. Bonding was performed following a full matrix of four bonding temperatures of $100,120,150$ and $170{ }^{\circ} \mathrm{C}$ and three bonding forces of 1,5 and $10 \mathrm{~N}$. The bonding temperatures are defined as the temperature measured using a thermocouple inside the adhesive, below the chip. The bonding times at each temperature were selected as recommended by the supplier, see Table 1 . The conductive structures were printed using Dupont 5025 Ag-filled screen printing paste on a DEK Horizon 03i screen printer. Curing of the paste was performed in a conventional oven by heating the substrates for a period of 20 minutes at $120^{\circ} \mathrm{C}$.

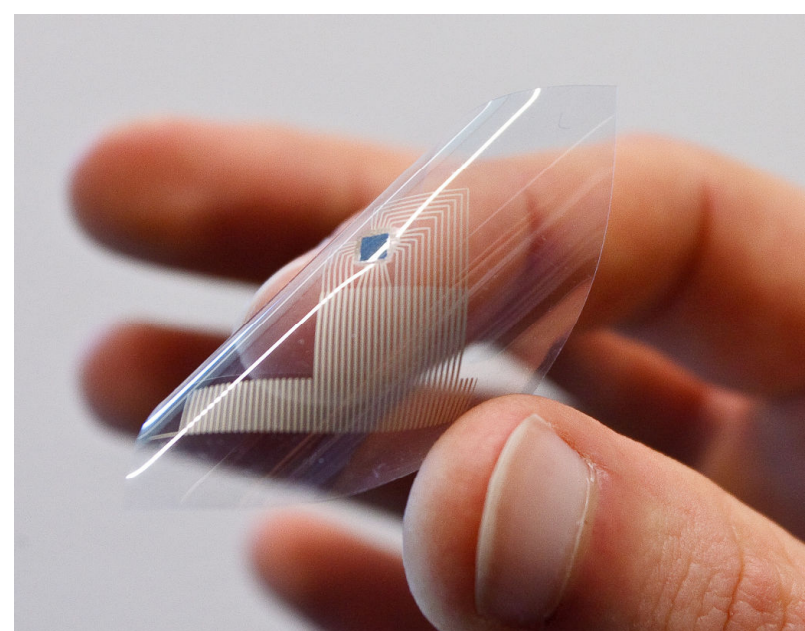

Figure 2. Photograph of typical foil with screen printed circuitry and attached ultrathin chip.

Using the best setting obtained for bonding on screen printed circuitry, the bonding was demonstrated to also work on fine pitch embedded circuitry. Bonding on embedded circuitry PEN foils was investigated using a $5 \mathrm{x}$ $5 \mathrm{~mm}$ IZM42 daisy chain test chip having 168 IO's, a pitch of $50 \mu \mathrm{m}$ and a thickness of $20 \mu \mathrm{m}$. Bonding temperatures of 120 and $150{ }^{\circ} \mathrm{C}$ and bonding forces of 10 and $40 \mathrm{~N}$ were investigated. The bonding forces were chosen to give the same bonding force per bump. A dedicated fanout circuitry was fabricated for this chip which allowed accurate $4 \mathrm{p}$ measurements on a portion of the chip bumps to circuitry interconnects. The bonding tool, procedure and adhesives were the same as for bonding on screen printed circuitry.

The process for making the embedded circuitry is discussed in detail elsewhere [2]. Grooves with an initial width of $25 \mu \mathrm{m}$ and a depth of $10 \mu \mathrm{m}$ were photoablated into the foil using a $\mathrm{KrF}$ excimer laser $(\lambda=248 \mathrm{~nm}$, repetition rate $300 \mathrm{~Hz}$, energy $10 \mathrm{~mJ} /$ pulse). These grooves were subsequently filled with an Inktec PA-010 nano-Ag screen printing paste using a conventional screen printer squeegee mounted in a dedicated tabletop filling tool. Curing of the material was performed in a conventional oven at a temperature of $120^{\circ} \mathrm{C}$ for a period of 20 minutes.

\section{Results and discussion}

\section{Bonding on screen printed circuitry}

\section{Visual inspection and initial contact resistances}

Flip chip bonding on screen printed circuitry was performed both on the thermally stabilized PEN and PET foils. The bonding temperature (as measured in the adhesive using a thermocouple below the die) was varied between 100 and $170{ }^{\circ} \mathrm{C}$ and the bonding force between 1 and $10 \mathrm{~N}$. 

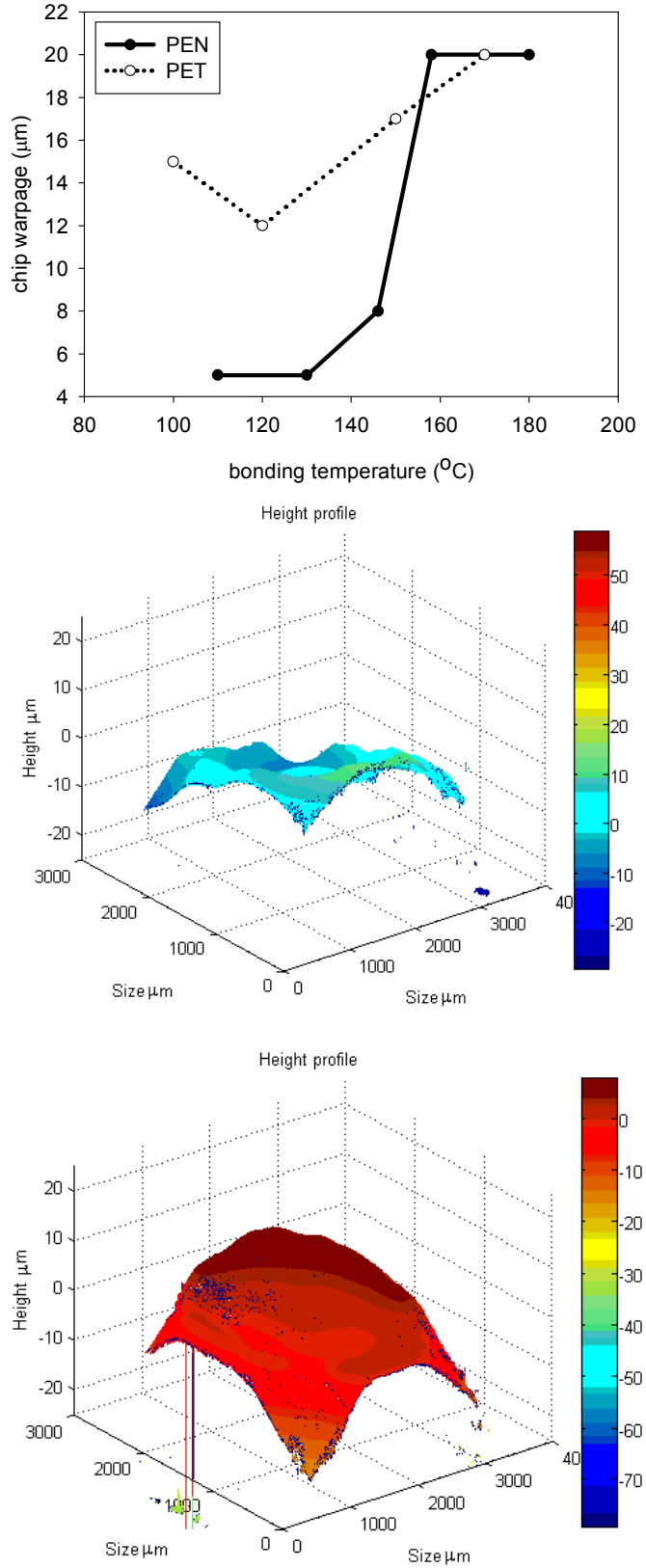

Figure 3. Chip warpage as a function of temperature for both PEN and PET. Top plot: chip warpage trends as a function of bonding temperature. Middle graph: $\mathrm{PEN}, 100{ }^{\circ} \mathrm{C}$ bonding temperature.

Bottom graph: PET, $100^{\circ} \mathrm{C}$ bonding temperature.

The corresponding bonding times at each temperature were taken according to the recommendation of the supplier, see Table 1. For each setting 3 samples were manufactured to get statistical data. The samples were visually inspected and electrical measurements were performed to determine initial contact resistances. As an illustration, Figure 2 shows a photograph of a typical example of a screen printed foil with attached ultrathin Si chip.

The visual inspection showed two clear trends. As a function of increasing bonding force, the chip bumps became increasingly compressed into the screen printed foils, as could be visually observed from the backside. At the highest force of $10 \mathrm{~N}$, chip fracture was consistently observed. Apparently this force is too high for these ultrathin and fragile chips. No clearly evident differences between PEN and PET were observed.

As a function of increasing temperature, microscopic and visual inspection of the foils showed increasing foil deformation in the full chip bonding area and also increasing chip warpage. This phenomenon was observed to be similar for all bonding forces but considerably more severe for PET than for PEN. The PEN foils did not show macroscopic foil deformation at bonding temperatures of 100 and $120{ }^{\circ} \mathrm{C}$. Confocal laser microscopy experiments were performed to quantify the chip warpage. Figure 3, top shows the trend for chip warpage as obtained from these experiments. The surface plots below show illustrative examples of the results obtained at the lowest bonding temperature of $100{ }^{\circ} \mathrm{C}$ for both PEN (middle) and PET (bottom). The results show that at 100 and $120{ }^{\circ} \mathrm{C}$ the chip is relatively flat on PEN while on PET already curvature was observed. In the temperature range of $130-$ $150{ }^{\circ} \mathrm{C}$ the warpage on PEN rapidly increases to values similar as for PET. These trends are consistent with the differences in macroscopic foil deformation that were observed.

To test functionality of the bonded chips, $4 p$ electrical measurements were performed to measure the initial bump-circuitry contact resistances. Figure 4 summarizes the obtained results for both PEN and PET. Because of chip fracture, the samples made with a bonding force of $10 \mathrm{~N}$ were not further considered.

The results show that across the full temperature and force range, a contact resistance of on average $80 \mathrm{mOhm}$ is obtained. The coefficient of variation (\%) was low at around $5 \%$ and none of the samples showed open contacts. Apparently, the clearly observed differences in foil deformation and chip warpage do not lead to differences in initial contact resistance for the considered bonding temperatures and materials.

\section{Lifetime and flexural testing}

Two different types of lifetime experiments were performed on the bare, bonded chips on the two different types of polymer foils. A protective layer or coating was not present to protect the chips during the tests. Accelerated humidity testing was performed at $60{ }^{\circ} \mathrm{C} / 90 \%$ $\mathrm{RH}$ for the samples bonded at $120{ }^{\circ} \mathrm{C}$ and $150{ }^{\circ} \mathrm{C}$ and both bonding forces for a period of up to 500 hours. The results are summarized in Figure 5. Temperature shock testing was performed at $-40{ }^{\circ} \mathrm{C} / 85{ }^{\circ} \mathrm{C}$ with a cycling period of 30 minutes for all four bonding temperatures and for both bonding forces. The results of this are summarized in Figure 6. Overall, the lifetime test results show that the bonds are very stable and do not show major degradation in the tests during the considered period. The accelerated humidity testing results show that the samples remain stable up to 500 hours. Even though clear trends 

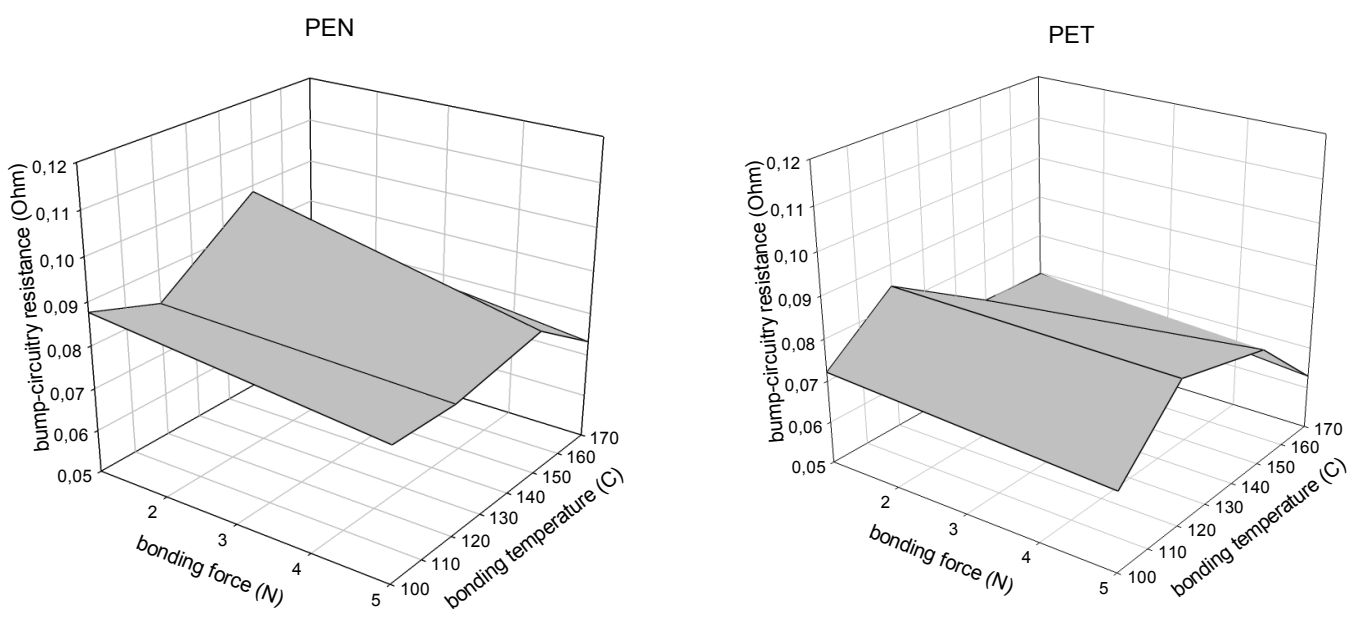

Figure 4. Plots showing initial bump-circuitry contact resistance (Ohm) for flip chip bonding of ultrathin test chip on screen printed circuitry on PEN and PET foils as a function of bonding temperature and force.

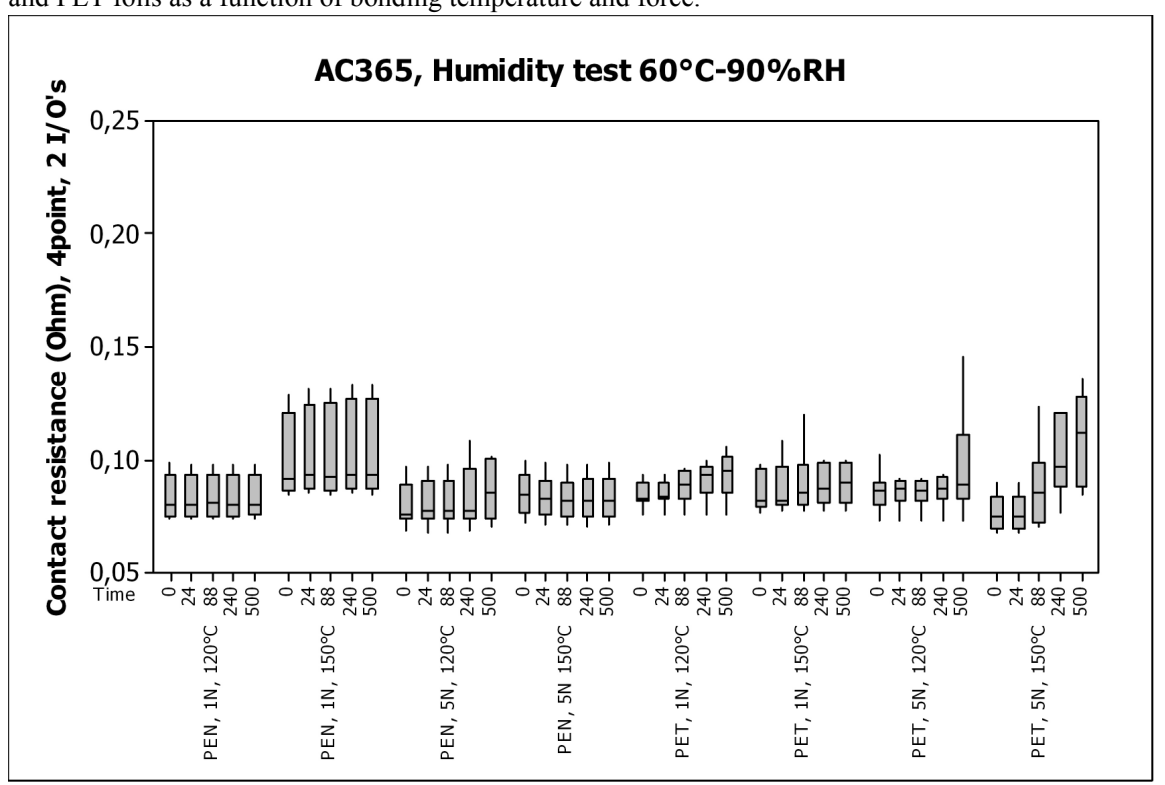

Figure 5. Accelerated humidity testing $\left(60{ }^{\circ} \mathrm{C} / 90 \% \mathrm{RH}\right)$ results for flip chip bonding of ultrathin dies on PEN and PET foils as a function of temperature and bonding force.

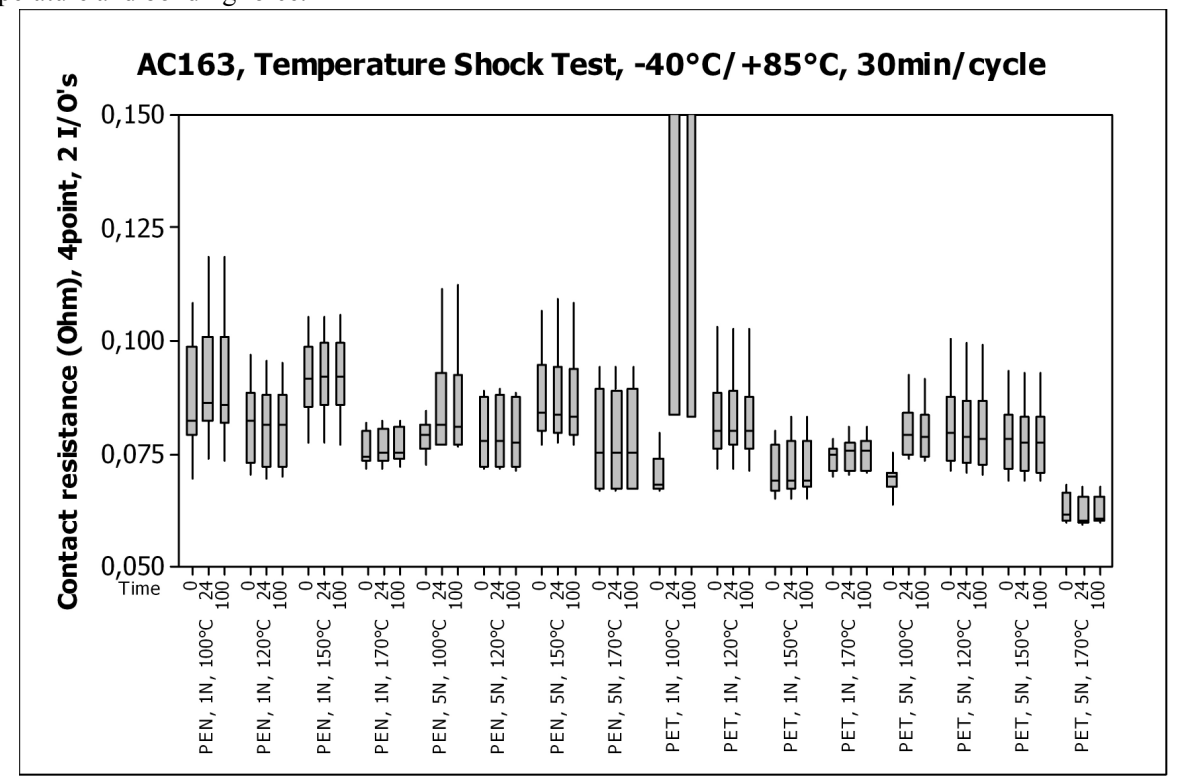

Figure 6. Temperature shock testing results $\left(-40 / 85^{\circ} \mathrm{C}, 30\right.$ minutes cycling time) for both PEN and PET as a function of temperature and bonding force. 
are hard to extract it appears that mainly the PETbased samples show slightly more degradation than the PEN-based samples. Continued exposure should show whether indeed clear trends become visible. The temperature shock tests show similar results. Also here, the majority of the samples remain stable within the considered number of cycles. Only one of the samples bonded at the lowest bonding force of $1 \mathrm{~N}$ and $100{ }^{\circ} \mathrm{C}$ show a significant degradation. This behavior however was only observed for one of the test samples. More temperature shock tests in a wider range of temperatures need to be undertaken.

Testing of the flexural durability of the bare, bonded chips on PEN foil at a bonding temperature of $120^{\circ} \mathrm{C}$ was investigated using a custom-built flextester. The substrate with the bonded chip is continuously bended in two directions by pulling it forward and backward over opposing cylinders. Testing was performed at bending diameters down to $10 \mathrm{~mm}$ for up to 250 bending cycles. No significant degradation in resistance and/or chip fracture could be observed within this period.

\section{Bonding on embedded circuitry}

\section{Introduction}

Screen printing is a well known and well-established method for making low cost electronic circuitry. A clear disadvantage however is that it is not possible to manufacture pitches / line spacings below roughly 150 $\mu \mathrm{m}$. Several novel technologies are and have been under development worldwide to manufacture low cost fine pitch electronic circuitry [3-9]. At the Holst Centre, a technology called 'embedded circuitry' has been developed [2]. The process consists of direct laser writing of grooves in a foil according to the required pattern and then filling these again with conductive screen printing paste using a screen printer squeegee. It was shown previously that with this technology it is possible to manufacturing conductive lines having a minimum width of $10 \mu \mathrm{m}$ at a line spacing of $25 \mu \mathrm{m}$. Using novel nano-Ag filled conductive pastes it was found to be possible to achieve resistances equivalent to around $3 \mathrm{x}$ bulk Ag.

\section{Bonding results}

Flip chip bonding on embedded circuitry was only done for PEN foils and in a smaller range of temperatures $\left(120\right.$ and $\left.150{ }^{\circ} \mathrm{C}\right)$ and bonding forces $(10$ and $40 \mathrm{~N})$ than for screen printed circuitry. A special test circuitry was manufactured for this purpose having a line width of 25 $\mu \mathrm{m}$ and a pitch of $50 \mu \mathrm{m}$ at the position of the chip. As an illustration, Figure 7 shows the daisy chain chip attached to this circuitry.

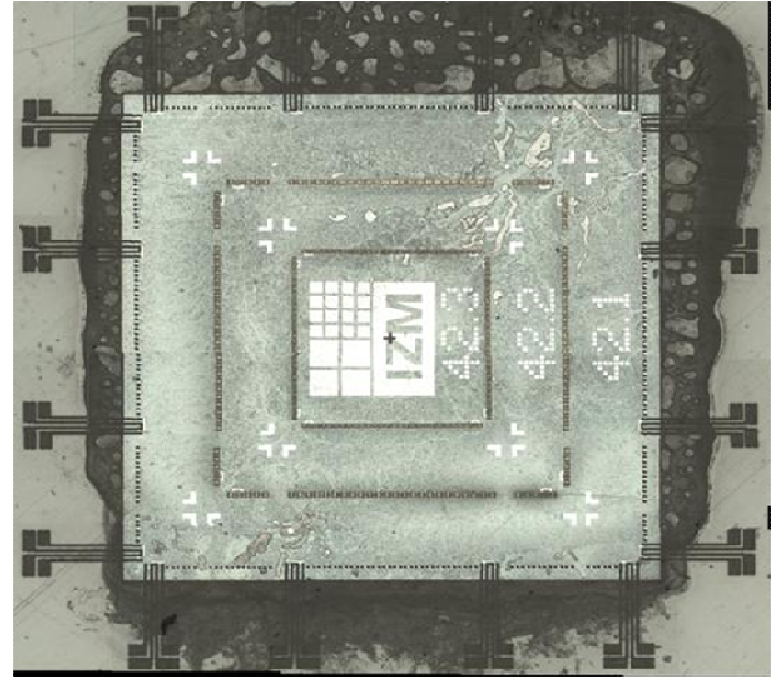

Figure 7. Microscopic photograph from backside of the foil with IZM daisy chain chip bonded to embedded circuitry. Line width is $25 \mu \mathrm{m}$, pitch is $50 \mu \mathrm{m}$.

Taken into account the differences in bump size, the initial bonding contact resistances (typically 300 $\mathrm{mOhm} /$ contact) were comparable to those obtained for screen printed circuitry. Like for bonding on screen printed circuitry, also here, no clear influence of bonding temperature and force was observed.

The coefficient of variation of the resistances and the number of open contacts was however larger than obtained for screen printed circuitry. This could be attributed to slight misalignments of the chip. The challenge to correctly place the large $(5 \times 5 \mathrm{~mm})$ very flexible chip with the high accuracy needed was found to be close to the limit of the bonding equipment that was used. A limited lifetime and flexural reliability evaluation showed good stability, similar as observed for screen printed circuitry.

\section{General discussion of the results}

The results discussed show that it is possible to achieve very reliable bonding of ultrathin dies with a low contact resistance and a good lifetime and flexural durability on low cost printed electronics PEN and PET foils. Similar good results were achieved on both screen printed circuitry and on the complementary fine pitch embedded circuitry. For a wide range of bonding temperatures and bonding forces, the bonding temperature does not largely affect the initial resistances or the lifetime and flexural durability. Even bonding at a temperature well above the $T_{g}$ was found to give good results. Visually however, a clear influence of the $\mathrm{T}_{\mathrm{g}}$ on the bonding was macroscopically observed as foil deformation in the chip bonding area and warping of the chip. For PET $\left(\mathrm{T}_{\mathrm{g}} \sim 85\right.$ ${ }^{\circ} \mathrm{C}$ ), this was observed in the full studied bonding temperature range of $100-170{ }^{\circ} \mathrm{C}$ while for PEN $\left(\mathrm{T}_{\mathrm{g}} \sim\right.$ $130{ }^{\circ} \mathrm{C}$ ), this was observed to only occur above approximately $140^{\circ} \mathrm{C}$, see Figure 3 .

A finite element study is currently being performed to further investigate the exact mechanism that can explain the observed results. This study is not yet completed but 
first results indicate that the behavior can be fully explained by the fact that above $\mathrm{T}_{\mathrm{g}}$ there is a significant increase in the CTE of the polymer. During the bonding process, the thin foil will be completely heated in a short timeframe through the heated bonding tool. When the temperature in the foil passes $\mathrm{T}_{\mathrm{g}}$ it will weaken and also will show a larger thermal expansion than below $T_{g}$, see Table 1. Initially, the foil can expand freely without disturbing the chip because the adhesive is not yet cured. In the course of the bonding process, the adhesive will cure and this will fix the chip to the foil. When the foil is cooled down after the bonding, it will revert back to its original state but it can no longer freely do so because it is now fixed to the chip. Because of its thickness, the foil is stronger than the chip and as a result its shrinkage will still occur, thereby warping the chip. For PEN, the $T_{g}$ is around $130{ }^{\circ} \mathrm{C}$. As a result, significant chip warpage is only observed for the bonding temperatures above this. For PET; the $\mathrm{T}_{\mathrm{g}}$ is significantly lower at $85{ }^{\circ} \mathrm{C}$. The studied range of bonding temperatures is above this temperature and consequently, chip warpage is observed for the full temperature range.

For the daisy chain chips that were tested here, the warpage of the chips (peak values of around $20 \mu \mathrm{m}$, see Figure 3) over the chip length of $2 \mathrm{~mm}$ did not seem to influence their operation. This corresponds well with values reported in the literature for acceptable warpage values for thin $\mathrm{Si}$ dies $[10,11]$. This is an important conclusion as it implies that high bonding temperatures and corresponding low curing times, see Table 1, can be used for bonding on both PEN and PET foils. The latter is important because the low cost electronic products that are under consideration are preferably made using roll-toroll manufacturing processes [12] which require fast throughput for the chip placement and interconnection.

If for some reason, chip warpage has to be completely prevented, the bonding temperature should be chosen below the $T_{g}$ of the polymer. For PEN foils, this is not a problem as already the currently studied ACA can give a reliable bonding. For PET foils, this is more of an issue as then the bonding temperature should be kept below $85{ }^{\circ} \mathrm{C}$. This would require the usage of very low temperature curing ACA's which as far as known have only very recently become available by various suppliers.

\section{Conclusion}

Flip chip bonding of ultrathin dies on low cost thermally stabilized PEN and PET foils has been performed for a range of temperatures and bonding forces and on two different types of low cost electronic circuitries. Based on the results it can be concluded that a reproducible, low contact resistance and a good lifetime and flexural durability can be achieved over a wide range of bonding forces and temperatures, even above the Tg of the polymer. Bonding at temperatures above the $T_{g}$ of the polymer was found to result in chip warpage. The amount of warpage was however found to be acceptable and did not result in chip damage for the considered daisy chain test chip.

\section{References}

1. Fjelstad, J., Flexible Circuit Technology. 3rd ed. 2007: BR Publishing Inc.

2. van den Brand, J., et al., Flexible embedded circuitry: A novel process for high density, cost effective electronics. Microelectronic Engineering. In Press, Corrected Proof.

3. Wang, J.Z., et al., Dewetting of conducting polymer inkjet droplets on patterned surfaces. Nature Materials, 2004. 3(3): p. 171-176.

4. Tan, B., K. Venkatakrishnan, and K.G. Tok, Selective surface texturing using femtosecond pulsed laser induced forward transfer. Applied Surface Science, 2003. 207(14): p. 365-371.

5. Niizeki, T., et al. Laser sintering of $\mathrm{Ag}$ nanopaste film and its application to bond-pad formation. in Electronic Components and Technology Conference, 2008. ECTC 2008. 58th. 2008.

6. Sankir, N.D. and R.O. Claus, An alternative method for selective metal deposition onto flexible materials. Journal of Materials Processing Technology, 2008. 196(1-3): p. 155-159.

7. Pique, A., et al., Embedding electronic circuits by laser direct-write. Microelectronic Engineering, 2006. 83(1112): p. 2527-2533.

8. Jung, P.G., et al., A micropatterned metal embedding process for the formation of metal lines in flexible electronics. Journal of Micromechanics and Microengineering, 2008. 18(3): p. 6.

9. Chung, J.W., et al., Conductor microstructures by laser curing of printed gold nanoparticle ink. Applied Physics Letters, 2004. 84(5): p. 801-803.

10. Banda, C., et al., Flip chip assembly of thinned silicon die on flex substrates. Ieee Transactions on Electronics Packaging Manufacturing, 2008. 31(1): p. 1-8.

11. Wu, A.T., et al., In Situ Measurements of Thermal and Electrical Effects of Strain in Flip-Chip Silicon Dies Using Synchrotron Radiation X-rays. Journal of Electronic Materials, 2009. 38(11): p. 2308-2313.

12. van den Brand, J., et al., Systems-in-foll - Devices, fabrication processes and reliability issues. Microelectronics Reliability, 2008. 48(8-9): p. 11231128. 